\title{
STRATEGI RESILIENSI MUSEUM DAN GALERI FOTO JURNALISTIK ANTARA MENGHADAPI PANDEMI COVID-19
}

\author{
Nurul Aldha Mauliddina Siregar \\ Ute Lies Siti Khadijah \\ Evi Novianti \\ Program Studi Pariwisata Berkelanjutan \\ Sekolah Pascasarjana Universitas Padjadjaran \\ Jalan Dipatiukur No. 35, Bandung, Jawa Barat \\ No Hp.: 085718442, E-mail: nurul.aldha@gmail.com
}

\begin{abstract}
ABSTRAK
Pelaksanaan kebijakan Pembatasan Sosial Berskala Besar (PSBB) sebagai upaya menekan angka penularan kasus pandemi Corona Virus Disease 2019 (Covid-19) di Jakarta mengharuskan sejumlah situs cagar budaya seperti museum menutup akses fisik untuk dikunjungi. Di tengah keterbatasan itu, Museum dan Galeri Foto Jurnalistik Antara (GFJA) melakukan terobosan dengan pendekatan digitalisasi museum menggunakan teknologi video reality (VR). Tujuan penelitian ini adalah untuk mengkaji strategi resiliensi museum dan GFJA dalam memberikan alternatif baru bagi masyarakat untuk tetap mengunjungi dan mengakses program serta kegiatan pameran foto jurnalistik yang secara berkala telah dilaksanakan di Museum dan GFJA selama ini. Penelitian ini dilakukan dengan menggunakan metode kualitatif dengan pendekatan deskriptif. Hasil penelitian menunjukkan bahwa kunjungan masyarakat dengan menggunakan metode VR lebih banyak. Narasi kekuatan pesan dari karya foto jurnalistik pun bisa disampaikan tanpa mengurangi sisi estetik citra suatu karya seni. Langkah ini menjadi salah satu bentuk apresiasi seni dalam pameran fotografi karena mampu menghubungkan masyarakat luas dengan karya foto jurnalistik tanpa batasan ruang. Dengan demikian, strategi pengelolaan museum ini dapat dijadikan role model bagi pengembangan museum atau cagar budaya dan penyelenggara pameran foto jurnalistik untuk masa yang akan datang.
\end{abstract}

Kata kunci: resilience, museum, jurnalistik, pandemi Covid-19, virtual

\section{ABSTRACT}

Strategy of Resilience of the Antara Museum and Gallery of Photojournalism in Facing the Covid-19 Pandemic. The implementation of the Large-Scale Social Restrictions (PSBB) policy in an effort to reduce the number of transmission of the Coronavirus Disease 2019 (Covid-19) pandemic in Jakarta requires a number of cultural heritage sites such as museums to close physical access to visits. In the midst of these limitations, the Antara Gallery of Photojournalism and Museum (GFJA) made a breakthrough with the digitalization approach of the museum using video reality (VR) technology. The aim of this research is to study the strategy of resilience of the museum and GFJA in providing a new alternative for the public to continue visiting and accessing journalistic photo exhibition programs and activities which have been regularly held at the Museum and GFJA so far. This research was written using a qualitative method with a descriptive approach. The results showed that more community visits using the VR method. The power of the narrative messages of the photojournalism could be delivered without reducing the aesthetic side of the image of the artwork. This step is a form of an art appreciation in a photography exhibition because it is able to connect the wider community to photojournalism works without space limitations. Therefore, the strategy of managing this museum could be a role model for developing museums or cultural heritage and organizing photojournalism exhibitions in the future.

Keywords: resilience, museum, journalism, Covid-19 pandemic, virtual 


\section{PENDAHULUAN}

Museum dan Galeri Foto Jurnalistik Antara (GFJA) adalah salah satu situs cagar budaya (cultural heritage) yang mempropagandakan agenda pameran event virtual selama masa pandemi baik luring melalui video reality (VR) ataupun daring melalui diskusi daring secara real time. Salah satu penelitian terdahulu pernah mencoba menghadirkan simulasi virtual reality untuk koleksi foto dalam pameran Indonesian Press Photo Service (IPPHOS) yang dilaksanakan di Museum dan GFJA. Hasilnya menunjukkan bahwa 52\% pengunjung merasa cukup jelas dengan kondisi pameran di GFJA, $32 \%$ lainnya merasa sangat jelas, $12 \%$ merasa kurang jelas, dan 4\% merasa tidak jelas. Sementara itu, $60 \%$ pengunjung merasa tertarik dengan aplikasi VR (Hidayat, 2017). Penelitian ini merekomendasikan untuk menjadikan teknologi VR sebagai salah satu alternatif melengkapi akses pengunjung melihat pameran.

Di luar situasi pandemi, Museum dan GFJA memang tergolong salah satu bangunan peninggalan zaman prakemerdekaan yang cukup ramai dikunjungi terutama oleh kalangan anak muda karena pendekatan program serta acara yang dibangun berbasis komunitas menjadi agenda yang terus dinantikan oleh para penikmat karya foto jurnalistik di tanah air. Sebagai situs cagar budaya kelas A, pengelolaaan Museum dan GFJA tidak ditangani oleh Dinas Pemerintah Daerah, tetapi berinduk pada Badan Usaha Milik Negara (BUMN) Lembaga Kantor Berita Nasional Antara (LKBN). Museum dan GFJA berada di Wilayah Pasar Baru, Sawah Besar. Menempati lokasi bekas kantor berita Antara yang berpindah ke Wisma Antara di Jalan Medan Merdeka Selatan pada tahun 1982. Gedung ini juga menjadi saksi sejarah penyiaran beritaProklamasi Kemerdekaan Indonesia pada 17 Agustus 1945.

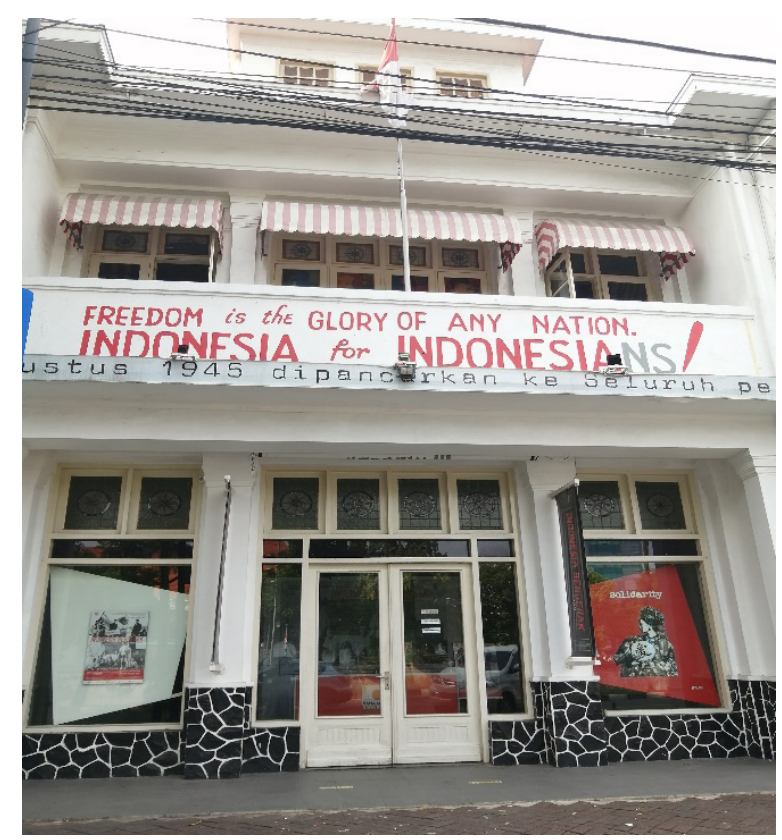

Gambar 1 Gedung Museum dan Galeri Foto Jurnalistik Antara

Sumber: Dokumen pribadi, 2020

Namun, gedung ini sempat terbengkalai karena kepindahan para staf karyawan LKBN Antara menempati gedung baru, kemudian atas inisiatif Handjodjo Nitimihardjo, Pemimpin Umum Kantor Berita Antara, pada 27 Desember 1992 Museum dan GFJA dirilis. Interior gedung digubah secara profesional oleh renovator museum, Dr. Wagiono Sunarto, M.Sc. Arsitekturnya dirancang bergaya art deco dan pop-art yang hingga saat ini masih tetap apik dan menarik. Lantai dasar digunakan sebagai ruang pameran. Sementara itu, lantai atas dijadikan museum dengan artefak alat pemancar radio, alat siar, dan diorama seputar proklamasi. Sejauh ini, pusat inti acara kegiatan di gedung ini berlangsung di lantai dasar, pameran fotografi. Adapun fungsi museum di lantai atas merupakan penguat pesan akan latar belakang gedung sebagai tempat memproklamasikan kemerdekaan tahun 1945 serta perjalanan dunia media di Indonesia. 


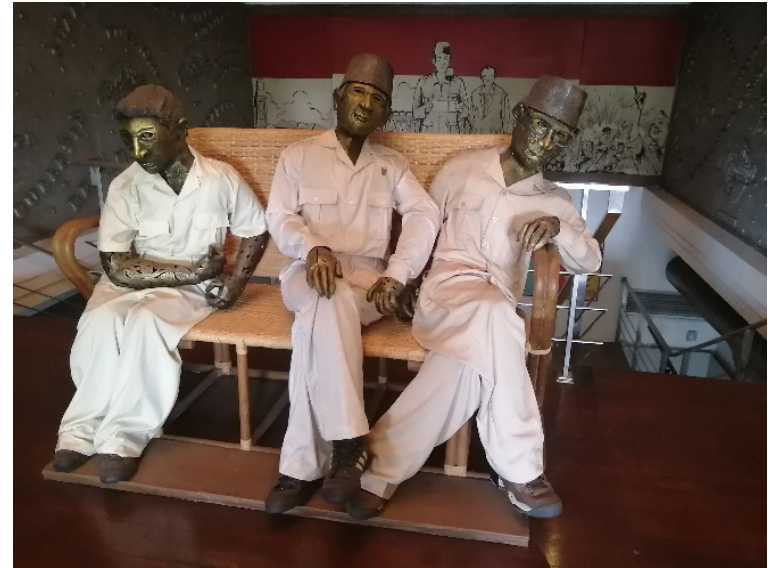

Gambar 2 Konsep pop-art menjadi gaya khas tampilan Museum dan GFJA

Sumber: Dokumen Pribadi, 2020

Tujuan dipugar dan difungsikannya kembali gedung yang termasuk peninggalan zaman prakemerdekaan itu menjadi situs museum dan galeri foto jurnalistik adalah untuk menarik minat kaum muda untuk berkecimpung di dalam dunia jurnalistik tanah air. Sejak didirikan, Museum dan GFJA secara rutin setiap tahun memamerkan karya-karya fotografi yang umumnya merupakan hasil karya Redaksi Foto Kantor Berita Antara. Agenda pameran ini menjadi satu program yang ditujukan untuk membuka wawasan baru perihal jurnalisme visual, khususnya foto jurnalistik.

Pada saat berdiri, Museum dan GFJA menjadi satu-satunya galeri foto yang ada di Asia Tenggara. Selang setahun kemudian, pada tahun 1993 melalui SK Gubernur DKI Jakarta No.475/1993 menyatakan bahwa gedung Museum dan GFJA merupakan gedung yang dilindungi. Pada tahun 1994, Joyce van Fenema, seorang kritikus Belanda menyatakan bahwa GFJA menjadi satu-satunya galeri fotografi yang ada di Asia dalam tulisan berjudul "Indonesian Photography: A Social Comitment" yang dibukukan dengan tajuk Photo Asia yang diterbitkan di Singapura. Dalam tulisannya Fenema mengungkapkan bahwa keberadaan GFJA merupakan simbol kebangkitan dunia fotografi Indonesia, serta wujud keberadaan fotografer Indonesia berada di tengah-tengah masyarakatnya yang terkumpul dalam komunitas hobi yang ekslusif (Tempo, 2000).

Museum dan GFJA menjadi salah satu arena berkumpulnya para penikmat apresiasi seni, khususnya seni kontemporer. Fotografer dari profesional hingga pemula hadir guna mengapresiasi karya seni foto jurnalistik yang dipamerkan. Beragam kalangan di luar fotografi dan jurnalistik pun hadir sekadar memenuhi rasa penasaran terkait event serta workshop yang dilaksanakan di sana. Workshop yang dilaksankan bertujuan untuk memenuhi pendidikan jurnalistik yang sangat langka di Indonesia (Antara, 2016).

Dengan bernaung di bawah LKBN Antara, segala bentuk pembiayaan menjadi tanggung jawab organisasi itu. Kerja sama pun kerap dijalin baik dari institusi lokal maupun internasional. Prinsip mengantarkan karya seni jurnalistik secara gratis menjadi daya tarik bagi masyarakat untuk melakukan kunjungan ulang di setiap pameran yang dilaksanakan. Motivasi masyarakat kalangan umum beragam, ada yang berangkat dari sisi edukasi keingintahuan tentang museum, ada juga yang ingin memenuhi kebutuhan seni mereka akan visual fotografi serta narasi berita yang menurut mereka bisa mereka akses secara mudah. Apalagi semakin berkembangnya industri fotografi menyebabkan banyak masyarakat tertarik untuk mengetahui dan mempelajari secara saksama. Hal ini merupakan sesuatu yang langka dan jarang terjadi di situs cagar budaya khususnya di Jakarta. 


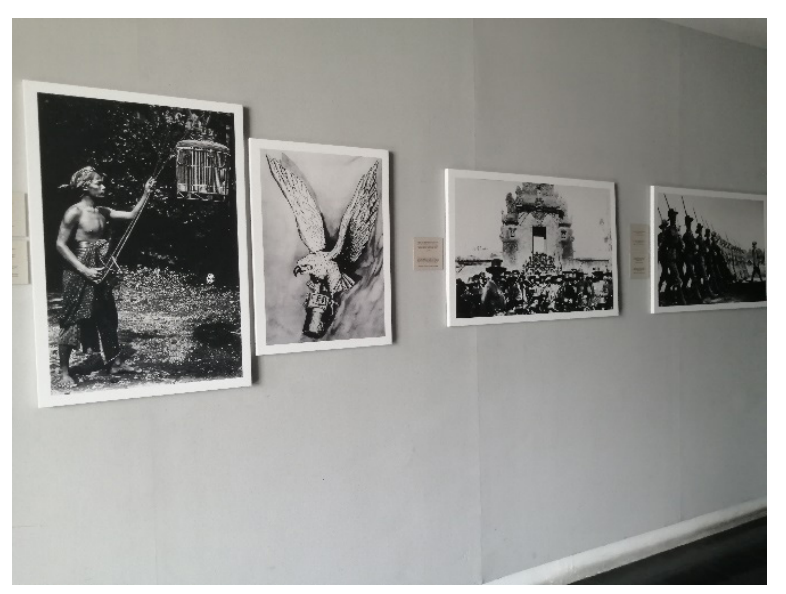

Gambar 4 Contoh karya-karya foto jurnalistik yang dipamerkan dalam kegiatan pameran di Museum dan GFJA Sumber: Dokumen Pribadi, 2020

Langkah-langkahyang dilakukanpengelola Museum dan GFJA adalah suatu terobosan yang bisa ditiru bagi penyelenggara situs cagar budaya mengingat minimnya minat masyarakat untuk berkunjung ke situs cagar budaya seperti museum. Menurut data Direktorat Pelestarian Cagar Budaya dan Permuseuman Kementerian Pendidikan dan Kebudayaan (Kemendikbud), sebanyak 435 museum yang terdaftar, 100 di antaranya berada dalam kondisi tidak layak. Menurut Fitra Arda Ambas, Direktur Pelestarian Cagar Budaya dan Pemuseuman Kemendikbud (2019) penyebab penurunan fungsi museum sebagai sarana publik disebabkan oleh beberapa hal, yaitu (a) perubahan kelembagaan, (b) tuntutan menghasilkan dana, (c) data yang tidak akurat/informasi koleksi, (d) kualitas SDM yang minim, dan (e) tidak memiliki program yang jelas (Setkab, 2020). Dengan demikian, disimpulkan kondisi museum di Indonesia tidak ubahnya seperti gudang penyimpanan benda pusaka. Hal ini mencerminkan bahwa poin penting atas peninggalan benda-benda yang tersimpan di museum tidak sampai kepada masyarakat sebagai suatu nilai pembelajaran yang patut dijaga keberlangsungannya.
Menurut data Asosiasi Museum Indonesia (AMI), per 2016 dari 428 museum di Indonesia 65 berada di Jakarta. Angka itu merupakan yang paling banyak di Indonesia (AMI, 2016). Namun, mirisnya dibandingkan wisata unggulan yang berada di Jakarta, seperti Taman Impian Jaya Ancol, Taman Mini Indonesia Indah, dan Kebun Bintang Ragunan, akumulasi kunjungan lima museum di Jakarta, yakni Monumen Nasional, Museum Nasional, Museum Satria Mandala, Museum Sejarah Jakarta, dan Pelabuhan Sunda Kelapa masih lebih rendah dibandingkan ketiga destinasi pariwisata unggulan di luar museum itu (Maulida, 2018). Kondisi ini lebih memprihatinkan di tengah situasi pandemi Covid-19 yang mulai terjadi pada awal Maret 2020. Pelaksanaan kebijakan Pembatasan Sosial Berskala Besar (PSBB) guna mengurangi tingkat penularan infeksi wabah telah menyebabkan operator museum di Jakarta terpaksa membatasi sampai menutup akses museum untuk masyarakat.

Padahal rekam jejak kekayaan suatu bangsa terpatri kuat dalam situs-situs warisan budaya (cultural heritage) yang dimilikinya. Secara defintif cagar budaya memiliki pengertian sebagai ekspresi cara hidup yang dikembangkan oleh suatu komunitas dan diwariskan dari generasi ke generasi, termasuk adat istiadat, praktik, tempat, benda, ekspresi, dan nilai seni. Cagar budaya sering dinyatakan sebagai Cagar Budaya Tak Berwujud atau Berwujud (ICOMOS, 2012). Kelestarian warisan budaya menjadi suatu cermin bagaimana menjaga pengetahuan tentang peradaban agar generasi ke depan bisa menghargai dan mengetahui bagaimana transformasi sejarah kehidupan sebelum mereka.

Sebagai negara kepulauan yang terdiri dari beragam suku, adat, bahasa, dan budaya, Indonesia adalah salah satu negara yang kaya 
akan warisan budaya baik benda maupun tidak benda. Kekayaan ini sayangnya belum disadari dan dilestarikan ditinjau dari kebanyakan situs cultural heritage di tanah air seperti museum yang kondisinya terbengkalai tidak terawat. Di tengah ancaman keterpurukan akan semakin minimnya kunjungan masyarakat ke museum karena dampak pandemi, museum-museum di tanah air memerlukan satu strategi resiliensi untuk tetap bertahan.

Tujuan penulisan artikel ini adalah untuk melihat bagaimana strategi resiliensi situs cagar budaya, dalam hal ini Museum dan GFJA mempertahankan keberlangsungannya menggelar sejumlah agenda pameran foto jurnalistik di tengah minimnya minat masyarakat mengunjungi museum ditambah ancaman krisis multidimensi akibat pandemi Covid-19.

\section{METODE}

Penelitian dilakukan dengan menggunakan metode kualitatif. Metode kualitatif deskriptif merupakan suatu pendekatan yang menitikberatkan penafsiran pada suatu fenomena yang ingin diketahui tentang siapa, apa, dan di mana suatu kejadian terjadi (Oun \& Bach, 2014).

Menggunakan pendekatan kualitatif dalam penelitian ilmiah bertujuan untuk mendeskripsikan fenomena secara detail atau terperinci dan mendalam. Dengan demikian, dalam penelitian ini tidak memandang bahwa besarnya sampling sebagai keutamaan pengumpulan data melainkan dengan menggunakan sampling dalam jumlah terbatas. Apabila data yang dikumpul telah mendalam serta mampu menggambarkan fenomena yang diteliti, tidak memerlukan sampling tambahan atau yang lainnya (Kriyantono, 2014)

Pendekatan kualitatif dicirikan dengan membangun teori dari data atau fakta kemudian mengembangkan sintesis atas interaksi serta teori-teori yang telah dibangun dari fakta-fakta mendasar (grounded) kemudian mengembangkan pengertian, dan sebagainya (Sahrah, 2020). Setidaknya, ada lima jenis metode yang digunakan dalam penelitian kualitatif yang banyak diaplikasikan, yaitu: (1) observasi terlibat; (2) analisis percakapan; (3) analisis wacana; (4) analisis isi; dan (5) pengambilan data etnografis (Somantri, 2005).

Dalam penelitian ini metode etnografis dipilih menjadi cara untuk mengumpulkan data dan informasi kepada narasumber yang terlibat dalam pengembangan Museum dan GFJA serta pengunjung yang datang. Adapun ciri metode etnografis yang tidak terstruktur serta memfokuskan pada kedalaman tekstur serta mengalir dari pengalaman- pengalaman yang secara selektif dari narasumber yang dipilih dengan melalui proses interaksi terhadap subjek penelitian dengan teknik wawancara secara mendalam sesuai untuk mendalami bagaimana narasumber dalam hal ini pengelola Museum dan GFJA melakukan strategi untuk meresiliensi agenda serta kegiatannya agar tetap berlangsung selama masa pandemi Covid-19.

Dalam mengaplikasikan metode kualitatif peneliti harus mempertimbangkan pemahaman yang dimiliki, baik dalam proses perencanaan maupun selama proses analisis, untuk meminimalkan bias akan diri sendiri (Elo et al., 2014). Untuk menghindari bias asumsi dari peneliti, pengumpulan data dilakukan triangulasi.

Triangulasi didefinisikan sebagai kegiatan pengecekan data dengan beragam sumber, teknik, dan waktu. Adapun tujuan triangulasi antara lain guna meningkatkan kekuatan teoretis, metodologis, dan interpretatif dari penelitian kualitatif (Sugiyono, 2017). Analisis data penelitian dilakukan dengan cara reduksi data, pemaparan data, dan simpulan. 
Pengumpulan data primer dalam penelitian ini dilakukan dengan wawancara mendalam (indepth interview) kepada pihak pengelola Museum dan GFJA dengan menyampaikan pertanyaan terbuka open-ended question. Sementara itu, data sekunder dikumpulkan dengan menggunakan studi terhadap literaturliteratur atau dokumen pendukung dan observasi. Creswell (2014) mendefiniskan observasi dalam penelitian kualitatif sebagai kegiatan pencatatan yang dilakukan oleh peneliti tentang perilaku dan kegiatan yang terjadi dalam suatu penelitian.

\section{PEMBAHASAN}

Berkunjung ke situs cagar budaya seperti museum termaksud dalam kegiatan pariwisata budaya (cultural tourism), tipe pariwisata yang dilakukan dengan mengunjungi aset budaya atau segala sesuatu yang ada kaitannya dengan kebudayaan masyarakat. Sebagai sebuah daya tarik wisata museum dapat digolongkan sebagai daya tarik wisata buatan (built environment attraction). Museum dibangun untuk kebutuhan pelestarian koleksi atau memuaskan manusia akan kebutuhan atas eksistensi suatu bendabenda peninggalan manusia (Junaid, 2017).

Permasalahan museum umumnya beragam. Museum yang dikelola oleh pemerintah umumnya menghadapi sikap pasif akibat mengandalkan pembiayaan dari APBN yang terbatas pada kewajiban sebatas perawatan dan penyimpanan koleksi. Berbeda dengan museum swasta, dana bukan hambatan karena bisa mengandalkan komunitas atau yayasan yang menaungi untuk keperluan museum. Namun, di samping dana kendala yang umum terjadi di berbagai jenis museum adalah pertimbangan sirkulasi pengunjung yang baik dengan alur sistem informasi yang jelas mengenai benda yang dipajang, koordinasi setiap objek yang dipamerkan dengan ruang lingkup pameran sering tidak diselidiki apakah informatif atau tidak bagi pengunjung yang ingin menikmati pameran (Yendra, 2019).

Guna menampilkan koleksi benda, museum ataupun sebuah galeri umumnya melaksanakan kegiatan pameran. Menurut (Wahab \& Zuhardi, 2013) pameran didefinisikan sebagai presentasi kompleks yang menyampaikan konsep, memamerkan objek, dan menggairahkan indra. Konsekuensinya, prinsip desain pameran seni harus melibatkan zona kenyamanan manusia diikuti oleh pendekatan estetika.

Foto jurnalistik adalah produk jurnalistik yang diproduksi oleh wartawan selain berita (straight news, hard news, berita tafsir, dan depth report), juga nonberita (artikel, feature, tajuk rencana, pojok, karikatur, dan surat pembaca (Laba et al., 2015). Foto jurnalistik berbeda dengan jenis fotografi lain ditinjau atas ketepatan waktu, artinya foto memiliki kronologi waktu untuk dipublikasikan. Objektivitas, situasi yang tergambar merupakan representasi jujur, dan narasi foto memiliki elemen berita yang memberi informasi yang mendalam kepada pembaca. Oleh sebab itu, foto jurnalistik merupakan alat komunikasi visual dan artefak budaya (Kędra, 2016) karena memiliki nilai sejarah terkait suatu kejadian yang bisa dipamerkan dalam satu kegiatan pameran seni.

Sejak didirikan secara konsisten Museum dan GFJA menyelenggarakan pameran foto jurnalistik serta workshop dengan tajuk serta tema pilihan guna mendekatkan dunia jurnalistik kepada masyarakat terutama generasi muda. Kilas balik menjadi tajuk pameran yang diselenggarakan secara berkala sejak Museum dan GFJA dibuka untuk umum pada tahun 1992. 
Tabel Judul tajuk pelaksanaan kegiatan Workshop Museum dan Galeri Foto Jurnalistik Antara

(1994-2016)

\begin{tabular}{ccc} 
No. & Workshop GFJA & $\begin{array}{c}\text { Tahun } \\
\text { Pelaksanaan }\end{array}$ \\
\hline 1 & Angkatan Perdana & 1994 \\
\hline 2 & Putaran Asa & 1995 \\
\hline 3 & Otak Kecil & 1996 \\
\hline 4 & Lintas Batas & 1997 \\
\hline 5 & Celah Masa & 1999 \\
\hline 6 & Menangkap Waktu & 2000 \\
\hline 7 & Imitation of Life & 2002 \\
\hline 8 & Silentium & 2003 \\
\hline 9 & Mata Kedua & 2004 \\
\hline 10 & Response & 2005 \\
\hline 11 & Rhythm Vision & 2006 \\
\hline 12 & Unbreakable & 2007 \\
\hline 13 & Glosarium & 2008 \\
\hline 14 & Mind Passion & 2009 \\
\hline 15 & Ennermousight & 2010 \\
\hline 16 & Carpe Diem & 2011 \\
\hline 17 & Imatajinasi & 2012 \\
\hline 18 & Seen & 2013 \\
\hline 19 & Unfinished & 2014 \\
\hline 20 & Pijar Lintang & 2015 \\
\hline 21 & Arkamaya & 2016 \\
\hline & &
\end{tabular}

Sumber: Antara, 2016

"Pengelolaan museum dan galeri ini dibawahi langsung pimpinan direktur umum LKBN Antara. Bukan CSR namun menjadi salah satu bentuk upaya Antara untuk menjangkau masyarakat dalam bentuk edukasi jurnalistik. Peruntukan awalnya untuk itu, menjangkau semua elemen masyarakat. Misinya adalah menjaga semangat perjuangan Antara. Karena Antara merupakan bagian sejarah kemerdekaan, usianya bahkan lebih tua dari Republik Indonesia, dengan nilai sebagai tempat bersejarah, di mana proklamasi dipancarkan, supaya ini tetap terjaga. Karena banyak yang tahu antara hanya sebatas media masa" (Patrizki, wawancara 14 Oktober 2020).
Mulai tahun 1992 hingga tahun 2020, Museum dan GFJA dipimpin oleh Oscar Motuloh sebagai penanggung jawab serta kurator. Pada Maret 2020, Oscar Motuloh memasuki usia pensiun digantikan oleh Ismar Patrizki sebagai penanggung jawab serta kurator Museum dan GFJA. Selama lebih dari 28 tahun beroperasi dinamika organisasi pun terjadi dalam tata kelola organisasi Museum dan GFJA, tetapi sampai hari ini kegiatan yang bertujuan melestarikan kemerdekaan dalam bingkai fotografi masih berlangsung meski harus dihadapkan oleh kondisi pandemi Covid-19. Optimisme pengelola untuk tetap menghadirkan pameran kepada pengunjung saat wabah pandemi Covid-19 diwujudkan dengan melaksanakan virtual tour di tiga agenda. Pameran tahun ini adalah Kilas Balik 2019, Indonesia Bergerak, dan Manunggal Negeri. Paling terakhir pada tahun 2020, Manunggal Negeri dilaksanakan bekerja sama dengan perwakilan Cabang Kantor Berita Antara di Nagroe Aceh Darusalam (NAD).

Sebelum dilaksanakan PSBB tahap II di Jakarta, Museum dan GFJA sempat dibuka dengan menerapkan adaptasi baru pelaksanaan protokol kesehatan bagi pengunjung. Pembatasan jarak fisik juga dilakukan dengan memasang rambu dan mengatur jumlah pengunjung di setiap sesinya. Namun, seiring ketatnya kembali aturan PSBB, pelaksanaan pameran juga disediakan secara virtual. Sesi daring secara real time berupa seremoni pembukaan dan workshop diskusi narasumber dilaksanakan dengan bantuan media sosial seperti Zoom atau live streaming melalui Instagram antara foto.com dan antaranews. com. Untuk sesi luring dengan memanfaatkan teknologi VR tampilan pameran bisa disajikan secara virtual kepada masyarkat secara jelas 
dengan narasi yang menyertai karya-karya foto jurnalistik layaknya melihat secara langsung di pameran dengan mengunjungi laman website antara foto (https://www.antarafoto.com/ indonesia-bergerak).

"Selama Covid-19 kegiatan sempat terhenti, Covid-19 menjadi tantangan karena kegiatan memang sudah harus jalan ya. Kita awal pandemi berunding dan memutuskan agar pameran tetap bisa berjalan, kita coba alternatif apa supaya tetap bisa jalan, kami buat platform virtual. Sehingga, tetap ada pameran, disajikan dalam bentuk fisik dan virtual. Positifnya menjangkau masyarakat lebih luas" (Patrizki, wawancara 14 Oktober 2020).

Video reality (VR) adalah penggunaan teknologi 3D yang dihasilkan komputer yang dapat dinavigasi dan mungkin berinteraksi, yang menghasilkan simulasi waktu nyata dari satu atau beberapa pengguna pancaindera (Guttentag, 2010; Errichiello et al., 2019). Aplikasi VR umumnya berbasis teknologi yang bisa digunakan wearable (seperti ponsel cerdas, arloji cerdas, dan HMDS) yang banyak digunakan dalam industri pariwisata yang digunakan untuk mentranformasi tampilan yang menyesuaikan dengan ekspektasi sudut pandang pengalaman wisatawan atau pengunjung destinasi pariwisata atau yang digunakan sebagai bentuk fasilitasi meningkatkan nilai tambah (Jung et al., 2016).

"Ga mesti VR dengan alat bantu, tapi VR yang bisa diakses lewat HP, awal Covid hampir tidak ada kegiatan, ditantang ke depan harus tetap berkegiatan. Mulai berpikir bagaimana pameran secara virtual dengan teknologi 360. Kita memang sudah ada platformnya tinggal operating. PRnya adalah pengambilan gambar, tim murni mengerjakan sendiri. Membuat VR itu ga cuma butuh alat, tapi SDM yang paham untuk menyajikan gambar secara riil" (Patrizki, wawancara 14 Oktober 2020).
Sebagaimana fungsinya, selain sebagai media merekam kenyataan, fotografi memiliki fungsi untuk mengekspresikan artistik (Ismanto, 2018). Keunggulan VR di Museum dan GFJA ialah kekuatan artistik gambar virtual yang dihasilkan sesuai dengan fungsi fotografi SDM yang sebagian besar adalah fotografer dan wartawan berhasil menghadirkan citra VR yang lebih artistik dengan disertai legenda narasi yang informatif. Sejalan dengan itu, menurut (Mathwick et al., 2001) syarat untuk menciptakan respons estetika yang baik dari pengalaman berkunjung ke museum di mata pengunjung atau penikmat seni dipengaruhi oleh dua hal, yaitu (1) daya tarik visual langsung dari museum desain pameran museum dan (2) aspek spektakuler dari pengalaman (persepsi hiburan dan hiburan yang dirasakan).

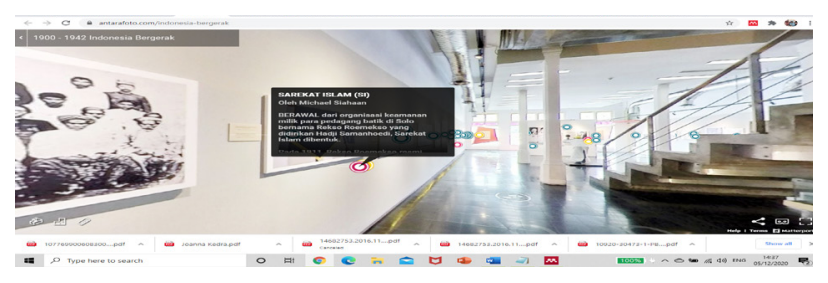

Gambar 4 Tampilan VR Pameran Indonesia Bergerak GFJA Sumber: https://www.antarafoto.com/indonesia-bergerak, 2020

Menurut pihak penyelenggara pameran, visitasi pengunjung ke acara pameran virtual ini cukup banyak, mencapai 5.000 kunjungan di tiga minggu. Sementara itu, umumnya secara riil masyarakat mengunjungi pameran di gedung Museum dan GFJA rata-rata mencapai 1.000 kunjungan per bulan. Hal ini senada dengan hasil penelitian yang mengungkapkan bahwa VR mendorong publikasi atau promosi dari keberadaan suatu situs budaya hingga menarik lebih banyak pengunjung (Huang et al., 2013; (Errichiello et al., 2019).

Inovasi ini juga menjadi satu kesempatan untuk penyelenggara pameran merangkul lebih banyak lagi penikmat foto jurnalistik di luar 
Kota Jakarta. Produktivtas yang tidak terhenti karena dampak pandemi ini menjadi sebuah adaptasi terobosan untuk para pengelola cagar budaya menghadapi situasi pandemi yang belum diketahui kapan akan berakhir. Hasil penelitian di Italia terhadap seratus museum terbesar di sana menunjukkan bahwa selama masa pandemi Covid-19 jumlah pengikut (follower) sosial media museum-museum di sana tumbuh dua kali lipat. Hal ini mengindikasikan penawaran narasi budaya melalui media daring menarik minat yang lebih besar, yang ditunjukkan oleh tren peningkatan pengikut (Agostino et al., 2020).

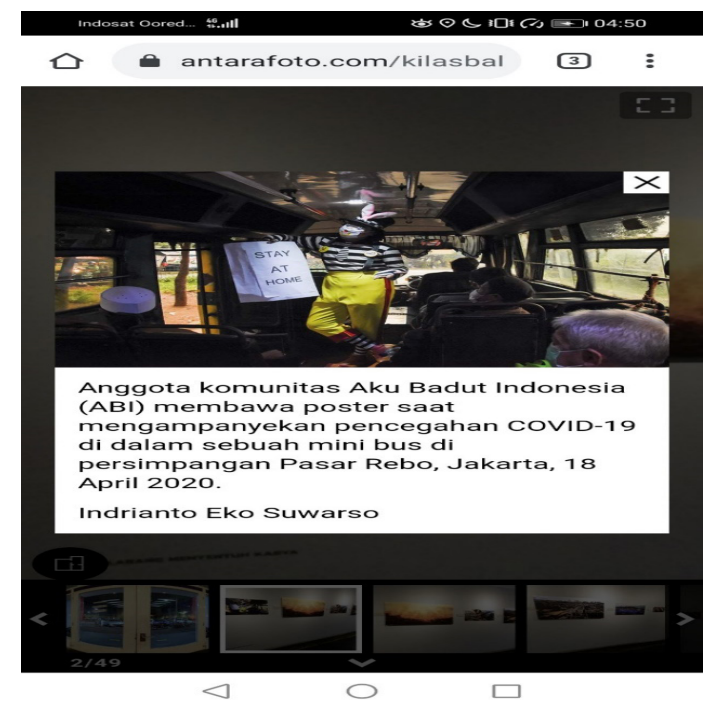

Gambar 5 Narasi yang ditampilkan dalam salah satu karya pameran foto kilas balik Sumber: Website Antara, 2020

Hal ini mendorong untuk mengedepankan beberapa pemikiran tentang potensi model apresiasi budaya yang diaktifkan secara digital yang memungkinkan untuk muncul pada masa depan. Ke depan pemikiran untuk menghadirkan kunjungan yang lebih santai, kunjungan yang lebih bertarget, kunjungan dan penayangan yang lebih dipersonalisasi, serta pengalaman digital dan fisik yang saling melengkapi.

"Keren, VR ini seolah mengajak kita jalan-jalan mengelilingi museum secara nyata. Setiap thumbnails diklik, keluar narasi penjelasan yang membantu pengunjung mengetahui terkait karya foto jurnalistik yang dipamerkan. Ini merupakan cara terbaik mengenalkan museum ke masyarakat awam dan mereka yang belum banyak mengenali museum" (Andari, Wawancara 5 Desember 2020).

"Fasilitas VR ini bisa dibilang salah satu inovasi yang terbukti dapat memudahkan interaksi masyarakat dengan sejarah. Alternatif untuk menambah intensitas masyarakat supaya aktif berinterakasi dengan sejarah dengan tetap memerhatikan koridor dan protokol yang tepat. Interaksi dengan sejarah merupakan hal yang mulai dilupakan, padahal cukup esensial untuk memupuk kecintaan terhadap negeri dan menguatkan persatuan bangsa. Dengan kemudahan seperti ini, semoga masyarakat semakin tertarik untuk mengenal warisan bangsa" (Siwi, Wawancara 5 Desember 2020).

Tentunya, tidak ada yang bisa menggantikan mengunjungi museum 'riil', tetapi model apresiasi seni dan budaya yang akan datang akan berbeda dan akan sangat kuat berakar pada penggunaan teknologi digital. Penelitian terhadap persepsi konsumen di Australia mengidentifikasi museum sebagai pengalaman di alam dan sebagai bagian dari sektor jasa. Mereka mengharapkan wawasan yang baik tentang keutamaan dari fungsi tampilan museum, bersama dengan kebutuhan bekerja untuk meningkatkan pengalaman di berbagai segmen pendidikan dan hiburan.

Hasil penelitian merekomendasikan bahwa untuk menciptakan masa depan yang berkelanjutan bagi museum perlu mengadopsi pendekatan yang berpusat pada layanan berpotensi untuk meningkatkan pengalaman pengunjung sehingga mampu menghasilkan kesuksesan jangka panjang (Alcaraz et al., 2009). 


\section{Mewujudkan Misi Berbasis Komunitas}

Museum dan GFJA turut membuka ruang pembelajaran jurnalistik bagi masyarakat. Diskusi-diskusi seputar jurnalistik sering diadakan guna memberikan informasi seputar perkembangan media jurnalistik ataupun foto jurnalistik. Dalam mengadakan pameran foto jurnalistik secara reguler GFJA menggandeng Redaksi Foto Kantor Berita Antara.

Umumnya pengunjung yang datang ke Museum dan GFJA beragam, kunjungan dari masyarakat yang melintas di kawasan Pasar Baru untuk berbelanja juga kerap terjadi, tetapi memang yang paling umum adalah kunjungan dari komunitas fotografi atau rombongan anak sekolah yang sedang melaksanakan study tour. Letak Museum dan GFJA yang strategis di tengah pusat keramaian Pasar Baru juga menjadi alasan dan daya tarik tersendiri.

Di samping Museum dan GFJA, LKBN Antara memiliki program untuk pendidikan jurnalistik tersendiri sebenarnya, yakni Lembaga Pendidikan Jurnalistik Antara (LPJA). Masyarakat yang ingin belajar fotografi secara komersial difasilitasi kurikulum pembelajaran yang dimentori oleh para fotografer profesional. Walaupun tidak berkaitan secara langsung, secara umum lulusan LPJA kerap mengakses GFJA guna mengasah pengetahuan jurnalistiknya. Adanya kegiatan edukasi ini membentuk satu simbiosis mutualisme antara Museum GFJA dan para fotografer yang menjadi lulusan LPJA ataupun fotografer lainnya.

Terbukanya akses Museum dan GFJA serta rutinnya kegiatan pameran menjadi salah satu cara bagi para fotografer lulusan LPJA cenderung untuk mengakses kebutuhan mereka mengasah seni fotografinya selepas pendidikan di LPJA dengan hadir atau terlibat di setiap pameran atau diskusi foto jurnalistik yang diselenggarakan.
"Saya mengenal Museum dan Galeri Foto Jurnalistik ini berawal dari pendidikan di LPJA. Kebetulan saya ikut kursus fotografi di tahun 2016, dulu LPJA masih di belakang museum, museum ini terbuka gratis untuk siapa saja, jadi saya selesai kursus suka lihatlihat museum lalu jadi tahu agenda apa saja yang akan dilaksanakan, dari awalnya cuma sekadar lewat saja, kadang -kadang jadi memantau ada kegiatan apa saja. Programnya juga ga ngebosenin Pameran, workshop, dikskusi sama fotografer senior yang hebat-hebat, tapi ada juga hiburan life music-nya. Itu menarik banget" (Yaka, Wawancara 5 Desember 2020).

Sementara itu, mereka yang berkecimpung di dunia pewarta foto sebagai fotografer media baik surat kabar, majalah, maupun berita daring di Jakarta menjadikan Museum dan GFJA sebagai ruang berkumpul di sela-sela pekerjaan baik untuk berteduh maupun berdiskusi lepas dalam agenda atau di luar agenda kegiatan Museum dan GFJA. Institusi lain seperti universitas, dinas pariwisata, kementerian, atau lembaga pemerintah juga kerap menjalin kerja sama. Mahasiswa juga dilibatkan sebagai tenaga sukarelawan menjadi SDM dalam kegiatan-kegiatan tertentu.

"Setiap pameran beda-beda, tapi tema umummnya tentang persatuan Indonesia, general Pancasila seperti apa. Setiap pameran juga kami menjaring kerja sama. Bentuk kerja sama yang kita lakukan beragam, dari dalam dan luar negeri, setiap kegiatan umumnya kita berpartner. Dua tahun terakhir kita distribusi ke daerah" (Patrizki, wawancara 14 Oktober 2020).

Dengan demikian, kegiatan pameran foto jurnalistik yang dilaksanakan tidak selalu dilakukan di gedung Museum dan GFJA, tetapi di mana saja di kota-kota yang menjalin kerja 
sama dengan Museum dan GFJA. Salah satu kerja sama yang dilaksanakan oleh Museum dan GFJA adalah Pameran Jakarta International Photo Summit (JIPS) yang secara rutin diselenggarakan tiga tahun sekali berkolaborasi dengan Dewan Kesenian Jakarta (DKJ) dan Galeri Nasional Indonesia. Agenda ini dimulai sejak tahun 2007 (Antara, 2016).

"Dulu kita punya workshop rutin, dua tahun terakhir berhenti karena belum menemukan kurikulum yang pas" (Patrizki, wawancara 14 Oktober 2020).

Kebebasan mengakses menjadikan Museum dan GFJA seolah menjadi 'rumah kedua' terutama bagi mereka anggota komunitas pewarta foto di Jakarta. Interaksi yang terbangun secara tidak langsung melahirkan beragam tautan komunikasi yang akhirnya menghadirkan beragam komunitas fotografi baru. Museum dan GFJA pun aktif dalam beragam platform sosial media Facebook dan Instagram dalam mempublikasikan kegiatan seputar agenda Museum dan GFJA.

Dalam konteks media jurnalistik, komunitas memegang peranan penting dalam membangun hubungan dengan pembaca serta bekerja sama guna mampu menghasilkan konten jurnalistik baik data, berita maupun gambaran yang lebih baik. Hubungan yang baik antara redaksi dengan komunitas mendukung hadirnya kolaborasi bersama antara pembaca dan redaksi media massa terutama dalam hal menghimpun pemberitaan. Dengan demikian, kedudukan komunitas dalam konteks jurnalistik amatlah penting.

Umumnya dalam industri media massa komunitas bisa berasal dari para pembaca setia yang memiliki passion di bidang fotografi atau jurnalistik. Fungsi komunitas berbedabeda tergantung media yang memfasilitasinya.
Namun, umumnya anggota dari komunitas suatu media massa atau pun fotografi akan dilibatkan dalam proses jurnalistik dalam media tersebut (Khairunnisa et al., 2020).

"Setiap agenda biasanya kami mengundang komunitas karena di sini memang tempat komunitas-komunitas berkumpul baik komunitas fotografi maupun komunitas seni lainnya. Setiap ada kegiatan, kita undang mereka. Responsnya cukup baik. Di beberapa tahun terakhir kita juga sharing knowledge, kita gandeng dengan musik, teman penikmat musik bisa belajar menikmati fotografi, teman-teman fotografi juga dapat hiburan" (Patrizki, wawancara 14 Oktober 2020).

Urgensi atas keberadaan komunitas fotografi menyelenggarakan diskusi dan pertukaran interprestasi ialah timbulnya apresiasi karya yang secara berkelanjutan merekonstruksi karya-karya yang meningkatkan kualitas dari kedua pihak baik pencipta karya maupun penikmat karya.

Secara mendalam Prasetya (2009) mengungkapkan bahwa untuk menilai suatu karya seni seperti foto jurnalistik tidak bisa atas pendapat-pendapat tidak berdasar dengan ukuran yang tidak dipahami secara kualitas atau lebih pada subjektif atas rasa suka, unsur teknis semata merupakan suatu bentuk penilaian tidak bertanggung jawab. Penilaian terhadap karya foto jurnalistik membutuhkan situasi pemahaman dan penguasaan materi dengan baik. Sebab, suatukarya seni bersifat ekspresif bukan representasi hanya dianggap sebagai keindahan atau kemenarikan yang semu.

Dengan demikian, Museum dan GFJA di mata masyarakat umum merupakan sarana menjembatani pengetahuan terkait karya pers sebagai wujud seni kepada masyarakat. Sejauh ini, Museum dan GFJA menjadi satu-satunya ruang publik yang memiliki misi edukasi terkait jurnalistik. 
Fungsi museum dan galeri seni saat ini pun sudah bergeser tidak hanya untuk memamerkan karya seni semata, tetapi juga bisa difungsikan sebagai ruang publik yang digunakan sebagai acara kemasyarakatan, seperti seminar dan bedah buku. Tujuannya adalah mengasah intelektual masyarakat terhadap eksistensi museum itu sendiri serta menjauhi kesan eksklusif hanya untuk sebagian kalangan tertentu (Khoirnafiya, 2012).

Kesan fotografi sebagai suatu kegiatan yang mahal (Antopani, 2016) bisa ditepis dengan kemudahan mengakses ilmu serta hasil karyanya. Oleh sebab itu, memfungsikan museum dan galeri seni sebagai tempat acara (event) masyarakat memberikan satu stimulan bagi masyarakat untuk menjadikan museum dan galeri seni sebagai tempat alternatif untuk dikunjungi.

Bagi komunitas fotografi, Museum dan GFJA seperti ruang pendidikan informal bagi fotografer mengasah bakat visual mereka. Hal ini sejalan dengan pengertian museum seperti yang disampaikan oleh The International Council of Museum bahwa museum merupakan lembaga nonprofit secara permanen yang dalam pelayanan masyarakat terbuka mengakses, memperoleh, melestarikan, meneliti, berkomunikasi, dan melihat pameran, untuk tujuan studi, pendidikan, dan menikmati suatu karya seni. Karya yang dipamerkan di Museum dan GFJA tidak pernah dikomersialisasikan baik dalam bentuk jual beli maupun lelang (UNESCO, 2020).

"Kita sejauh ini belum ada transaksi bisnis. Adanya event sosial penggalangan dana, ga sampe jual foto, kita buat buku kumpulan foto siapa yang mau menyumbang silakan membeli buku, karena kita tidak profit oriented, lebih kepada masyarakat" (Patrizki, wawancara 14 Oktober 2020).
Menjadi organisasi nonprofit menciptakan satu ekosistem bernaung untuk para komunitas fotografi se-Indonesia yang secara timbal balik memberikan rasa memiliki yang tinggi (sense of belonging) menjadi pendorong di setiap kegiatan Museum dan GFJA untuk tetap eksis dan mengaktualisasikan diri.

Penelitian mengungkapkan bahwa salah satu motivasi pengunjung datang ke Museum Otago di New Zealand adalah untuk mendapatkan pengetahuan tentang lingkungan komunitasnya guna mencapai rasa memiliki sehingga membuat diri pengunjung merasa tidak seperti orang asing.

\section{SIMPULAN}

Operasional Museum dan GFJA melihat peluang di tengah sempitnya kesempatan untuk menjembatani masyarakat akan kebutuhan terkait program-program yang bisa dinikmati masyarakat di tengah krisis pandemi Covid-19. Pelaksanaan event pameran foto jurnalistik yang menjadi agenda rutin tidak terhenti, tetapi disajikan dalam bentuk virtual event.

Hasilnya, kunjungan masyarakat mencapai lebih dari 5.000 kunjungan dalam jangka waktu tiga minggu. Dibandingkan kunjungan secara aktual yang hanya mencapai 1.000 kunjungan per bulan. Namun, inovasi ini tentu tidak bisa menggantikan pengalaman melihat langsung karya fotografi dalam ruang pameran secara riil. Mendesain pengalaman virtual pengunjung selain menggunakan teknologi, tetapi juga memerhatikan daya tarik visual.

Museum dan GFJA melibatkan komunitas dalam setiap kegiatannya khususnya komunitas fotografi dan jurnalistik. Tujuannya adalah untuk meningkatkan nilai aktualisasi atas misi yang diemban, yaitu menarik minat anak muda terhadap dunia jurnalistik serta melestarikan pesan-pesan kemerdekaan. 
Urgensi atas keberadaan komunitas fotografi menyelenggarakan diskusi dan pertukaran interprestasi ialah timbulnya apresiasi karya yang mendorong untuk terus melaksanakan agenda pameran foto jurnalistik.

Dengan demikian, salah satu strategi meningkatkan eksistensi museum dan GFJA di tengah-tengah masyarkat adalah dengan melibatkan komunitas-komunitas. Permintaan komunitas menjadi dorongan untuk tetap aktif melayani masyarakat meski di tengah situasi pandemi Covid-19. Dalam konteks media jurnalistik komunitas memegang peranan penting dalam membangun hubungan dengan pembaca serta bekerja sama guna mampu menghasilkan konten jurnalistik baik data, berita, maupun gambaran yang lebih baik.

\section{KEPUSTAKAAN}

Agostino, D., Arnaboldi, M., \& Lampis, A. (2020). Italian state museums during the COVID-19 crisis: from onsite closure to online openness. Museum Management and Curatorship, $0(0), 1-11$. https://doi.or g/10.1080/09647775.2020.1790029

Alcaraz, C., Hume, M., \& Mort, G. S. (2009). Creating sustainable practice in a museum context:Adopting service-centricity in nonprofit museums. Australasian Marketing Journal, 17(4), 219-225. https://doi. org/10.1016/j.ausmj.2009.06.003

AMI. (2016). Daftar Museum Seluruh Indonesia. Asosiasi Museum Indonesia. https://asosiasimuseumindonesia.org/ anggota.html

Andari, T. S. (2020). Pengalaman menggunakan VR Musem dan GFJA. Hasil wawancara pribadi.

Antara. (2016). Histori Masa Depan. Kantor Berita Antara.

Antopani, T. (2016). Fotografi, Pariwisata, Dan Media Aktualisasi Diri. REKAM: Jurnal Fotografi, Televisi, Dan Animasi, 11(1), 31. https://doi.org/10.24821/rekam. v11i1.1293

Creswell, J. W. (2014). Research design: qualitative, quantitative, and mixed methods approaches (4th ed.). SAGE Publications.

Elo, S., Kääriäinen, M., Kanste, O., Pölkki, T., Utriainen, K., \& Kyngäs, H. (2014). Qualitative Content Analysis. SAGE Open, 4(1), 215824401452263. https:// doi.org/10.1177/2158244014522633

Errichiello, L., Micera, R., Atzeni, M., \& Del Chiappa, G. (2019). Exploring the implications of wearable virtual reality technology for museum visitors' experience: A cluster analysis. International Journal of Tourism Research, 21(5), 590-605. https://doi.org/10.1002/ jtr.2283

Guttentag, D. A. (2010). Virtual reality: Applications and implications for tourism. Tourism Management, 31(5), 637-651. https://doi.org/10.1016/j. tourman.2009.07.003

Hidayat, R. (2017). Virtual Reality Pameran Arsip dan Koleksi Indonesia Press Photo Service ( Studi Kasus: Galeri Foto Jurnalistik Antara). UIN Syarif Hidayatullah.

Huang, Y. C., Backman, S. J., Backman, K. F., \& Moore, D. W. (2013). Exploring user acceptance of 3D virtual worlds in travel and tourism marketing. Tourism Management, 36, 490-501. https://doi. org/10.1016/j.tourman.2012.09.009

ICOMOS. (2012). International Scientific Commitee on Cultural Tourism Principle and Practice. In Cultural Tourism for Community Development: 40 Years of the World Heritage Convention Vigan, Philippines, 5-10th November. http://icomos-ictc.org/wp-content/ uploads/2017/11/Publications-PDF-1Sue-Millar-Presidents-address-ViganPhilippines-2012.pdf

Ismanto, I. (2018). BUDAYA SELFIE MASYARAKAT URBAN Kajian Estetika Fotografi, Cyber Culture, dan Semiotika Visual. REKAM: Jurnal Fotografi, Televisi, Dan Animasi, 14(1), 67. https:// doi.org/10.24821/rekam.v14i1.2138

Junaid, I. (2017). Museum dalam perspektif pariwisata dan pendidikan. Dinas 
kebudayaan dan pariwisata provinsi sulawesi selatan.

Jung, T., Dieck, T., M. C., Lee, H., \& Chung, N. (2016). Effects of virtual reality and augmented reality on visitor experiences in museum. Springer.

Kędra, J. (2016). Enhancing visual literacy through interpretation of photo-genres: toward a genre typology of journalistic photographs. Journal of Media Practice, 17(1), 28-47. https://doi.org/10.1080/146 82753.2016 .1159451

Khairunnisa, S. N., Srimulyani, H., \& Zulfan, I. (2020). Konstruksi Makna Aktivitas Jurnalistik Bagi Pelajar Anggota Komunitas Hai School Crew. Jurnal Kajian Jurnalisme, 4(1), 75. https://doi. org/10.24198/jkj.v4i1.26614

Khoirnafiya, S. (2012). Peranan Museum Bagi Masyarakat Masa Kini. https://museumku. wordpress.com/2012/01/16/perananmuseum-bagi-masyarakat-masa-kini/

Kriyantono, R. (2014). Teknik praktis riset komunikasi. Prenada Media. Prenada Media.

Laba, K., Rusmiwari, S., \& Diahloka, C. (2015). Representase Visi Surat Kabar dalam Foto Jurnalistik. Jisip, 2(1), 15-19. https://publikasi.unitri.ac.id/index.php/ fisip/article/view/61

Mathwick,C., Malhotra,N.,\& Rigdon,E.(2001). Experiential value: Conceptualization, measurement and application in the catalog and Internet shopping environment. Journal of Retailing, 77(1), 39-56. https:// doi.org/10.1016/S0022-4359(00)00045-2

Maulida, L. (2018). Penerapan Datamining Dalam Mengelompokkan Kunjungan Wisatawan Ke Objek Wisata Unggulan Di Prov. Dki Jakarta Dengan K-Means. JISKA (Jurnal Informatika Sunan Kalijaga), 2(3), 167. https://doi.org/10.14421/ jiska.2018.23-06

Oun, M. A., \& Bach, C. (2014). Qualitative research method summary. Journal of Multidisciplinary Engineering Science and Technology, 1(5), 151-161.

Patrizki, I. (2020). Virtual tour di Museum dan GFJA. Hasil wawancara pribadi.

Prasetya, A. (2009). Apresiasi dalam fotografi : sebuah pengantar dalam membaca, memahami, dan mengapreseiasi fotografi. Journal Wimba, 01(1), 87-93.

Sahrah, A. (2020). Studi Indigenous Dengan Metode Kualitatif(Cetakan 1, Vol. 7, Issue 2). Gramasurya.

Setkab. (2020). Dari 435 Museum Terdaftar, Kemendikbud: 100 Museum Masuk Kategori Tidak Layak. https://setkab. go.id/dari-435-museum-terdaftarkemendikbud-100-museum-masukkategori-tidak-layak/

Siwi. (2020). Pengalaman menggunakan VR. Hasil wawancara pribadi.

Somantri, G. R. (2005). Memahami Metode Kualitatif. Makara, Sosial Humaniora, 9(5), 26.

Sugiyono. (2017). Metode Penelitian Kuantitatif, Kualitatif dan R\&D. Alfabeta.

Tempo. (2000). "Kematian" di Gedung Tua. https://majalah.tempo.co/read/ fotografi/112503/kematian-di-gedung-tua

UNESCO. (2020). Definition of Museum. UNESCO. http://uis.unesco.org/en/ glossary-term/museum

Wahab, M. H. A., \& Zuhardi, A. F. A. (2013). Human Visual Quality: Art Gallery Exhibition. Procedia - Social and Behavioral Sciences, 101,476-487.https:// doi.org/10.1016/j.sbspro.2013.07.221

Yaka, S. (2020). Museum dan GFJA dimata anggota komunitas fotografer. Hasil Wawancara Pribadi.

Yendra, S. (2019). Museum dan Galeri (Tantangan dan Solusi). Jurnal Tata Kelola Seni, 4(2), 103-108. https://doi. org/10.24821/jtks.v4i2.3088 